\title{
Experimental Study on Psychological Health Intervention in Innovative and Entrepreneurial Education for Colleges Students
}

\author{
Ma Huaifen, Zhu Fengxia, Zhang Sale, Zhang Yu, Li Xiaoming \\ Xi’an Peihua University, Xi’an Shaanxi, 710125
}

Keywords: innovative and entrepreneurial education; psychological intervention experiment

\begin{abstract}
Innovation and entrepreneurship of college students is an important researching issue of current higher education, encouraging college students to start their own business has become a new work in guiding college students in starting their career life. But in fact, the campus life and the career life are quite different; because of the lack of social experience, many college students would have some psychological problems when they graduate from school; especially, some students who choose to start their own business must tackle with a lot of problems because of the complicated social environment that is quite different with that in school. Therefore, the intervention for college students who decide to have their own business is very important. Based on the importance, this paper researches the intervention of psychological health in innovative and entrepreneurial education for college students.
\end{abstract}

In 2015, the General Office of the State Council of the People's Republic of China has put forward the opinion on "Comprehensively Deepening the Reform of Entrepreneurial Education in Colleges and Universities." it can be seen that startup among college students has become an important part of the current higher education, and at the same time, the social needs and college students' own demands also put forward higher requirements for innovative and entrepreneurial education in colleges and universities. From the current situation, many college graduates show anxiety, lack of self-confidence and other psychological problems at the very beginning of their career life, these problems are more obvious in the college graduates who have their own company. As we all know, entrepreneurial college students face a more complex environment than the staff students, so they need more good psychological quality and psychological health as the support; from the perspective of education, at present, many colleges and universities focus on teaching entrepreneurial knowledge and skills but neglect students' mental health problems. Psychological intervention can quickly help college students to have a good psychological state. Therefore, it is of great practical significance to integrate the psychological health intervention into the innovative and entrepreneurial education of the college students.

\section{Significances of integrating psychological intervention into the students' education of innovation and startup.}

\subsection{Improve the intervention effect of self efficacy}

In psychology and behaviorism, self efficacy refers to the individual's behavior choice in the face of difficulties and obstacles. That is to say, college students have the psychology of dealing with problems, such as the psychologies of tenacity, persistence, and so on. These are the necessary psychologies of college students' entrepreneurial ability and innovation quality. Only with these psychologies, college students can better face the plight of life and work, and then get out of the dilemma and achieve success. In psychological health intervention, there are many ways to improve the self efficacy of college students; taking substitution effect for example, it uses the virtue of the model to let the individuals try their best to be neck and neck with the models; at the some time, it associates the tasks with the uncompleted work, so as to affect and intervention the individuals, and ultimately improve the self efficacy. 


\subsection{Intervention effect of optimism}

Optimism is the foundation of success, especially for college students' innovation and setup education. Optimism is the basic mentality of college students after graduation. Optimism and self-confidence can not only affect college students' attitude towards affairs, but also enhance the subjective initiative of college students to face difficulties. In the current survey, pessimism is an important problem for many college students after graduation. Therefore, we should intervene in this aspect, and finally cultivate the optimistic personality of college students. By psychological intervention, college students can tolerate the past, enjoy the present and face the future positively, and finally achieve success.

\subsection{Intervention effect of hope}

According to American psychology management scientist Luthans----hope is a kind of goal-oriented motive force, and it can stimulate the driving force of the individual's demand, and then push up the individual's behavior. Hope is a gradual process of development, it is sequential and systematic. Every college student has their expectation, especially in the education of innovation and startup, it is more important to improve the hope of college students. Through psychological intervention, college students can set scientific goals, make reasonable completion plans, and finally guide or promote college students to build healthy and positive hopes.

\section{Connotation of psychological quality education of college students' innovation and startup}

The psychological quality of innovation and startup is the combination of innovative psychological quality and entrepreneurial psychological quality. Therefore, college students' innovative and entrepreneurial psychological quality education refers to the cultivation of college students' innovative psychological quality and entrepreneurial psychological quality, and the connotation includes four aspects:

\subsection{To cultivate the college students' consciousness of innovation and startup}

The consciousness of innovation and startup is the need and interest of college students for innovative and entrepreneurial activities. Only the consciousness leads to behavior, therefore, the consciousness of innovation and startup is the basis of innovative and entrepreneurial behavior of college students. In actual educational activities, the current higher education concept requires college students to have the innovative and entrepreneurial qualities, and at the same time, contemporary college students really have a very strong consciousness of independent entrepreneurship. However, it is difficult for most students to persist in the initial wish, abandon themselves to computer game, and do not want to make progress after entering university. Therefore, it is necessary to cultivate the innovative and entrepreneurial consciousness of college students and define the future goals of college students.

\subsection{To improve the college students' ability of innovation and startup}

Ability is the carrier that the individual to achieve the goal, innovative and entrepreneurial ability is the most important foundation for college students to complete innovative and entrepreneurial behavior. In general, innovative and entrepreneurial ability contains knowledge, innovative and entrepreneurial skills and abilities, as well as other abilities and psychological quality. The existed studies show that contemporary college students perform better in knowledge, skill and ability of innovation and startup, but other abilities and psychological qualities are weak, such as organizational ability, adaptability, teamwork, etc. These abilities and qualities are very important and critical in the innovative and entrepreneurial work of the college students. If they are lacking of these abilities, the goal will not be achieved. Therefore, it is necessary cultivate their innovative and entrepreneurial ability by means of innovative and entrepreneurship education.

\subsection{To cultivate the college students' personality of innovation and startup}

In related studies: optimism, positive, confident attitude and integrity, solid personality is the 
best personality characteristics in startup. Personality has a huge impact on innovative and entrepreneurial behavior. For example, if college students do not have a confident personality, they will not be able to determine whether they will succeed in their business. Therefore, it can be said that innovative and entrepreneurial personality is also a basic factor in college students' innovative and entrepreneurial activities, and innovative and entrepreneurship education is to cultivate college students' innovative and entrepreneurial personality, and to enhance students' self-confidence, so as to improve the sense of self efficacy in the process of innovation and startup, and ultimately ensure the success of innovative and entrepreneurial activities of the college students.

\subsection{To cultivate the college students' will of innovation and startup}

In college students' innovation and startup, the innovative and entrepreneurial will is a psychological process that college students constantly adjust their own behavior in order to achieve their goals, and overcome the difficulties in the road of innovation and startup. It can also be said that will is a kind of spiritual symbol. At present, many college students are full of enthusiasm in the actual innovation and startup, but once they encounter some problems, they lack perseverance and patience, and their willpower is very weak, which mainly shows that they can not face setbacks positively and they are prone to depression, anxiety and other psychological problems, these problems can be solved by the innovative and entrepreneurial education of college students, and the students' innovative and entrepreneurial also can be improved.

\section{Cases of applying the psychological health intervention to the college students' innovative and entrepreneurial education.}

\subsection{To combine the entrepreneurial education and psychological education systematically}

According to the investigation, the author finds out that although many colleges and universities have set up entrepreneurial courses, they have not corresponding psychological courses. The contents of entrepreneurship courses just focus on training students' entrepreneurial knowledge without psychological training. In some special situation, psychological quality is even more important than entrepreneurial skills in the college students' innovation and startup. Therefore, psychological health intervention is more important in the education of college students' innovation and startup. Therefore, it is necessary to combine innovative and entrepreneurial education with psychological education systematically at the very beginning.

In the aspect of combination, we should not only focus on the entrepreneurial knowledge and entrepreneurial skills of the college students, but also pay more attention to the cultivation of college students' psychological quality, combine with the requirements for the college students' innovative and entrepreneurial ability and personality, help the college students to establish correct psychological thinking and harmonious interpersonal relations, and set up good self consciousness, positive guidance so as to affect the psychological state of the college students.

In the aspect of cases, we can develop the students' self-confidence, optimism, etc through the positive psychological thought of American psychologist Seligman, for example, to let the students sing songs that are full of positive thoughts such as "I believe" and "stubbornness" in the course, so as to interfere with the students' psychological state imperceptibly. At the same time, in the classroom, we should respect the students' subject status, pay attention to the interaction in the classroom; we can also let the students deeply understand the startup, relieve the anxiety of the students by means of playing video, and let the students have the confident conception that----I can, so as to lay a solid foundation for the innovative and entrepreneurial education.

\subsection{Cases of situational imitation}

Situational imitation is based on a specific situation in order to let students imitate the real situation, from the current situation of innovative and entrepreneurial education for the college students, even if the contents of teaching materials and the explanation of teachers are perfect, but they can not show the actual process of the innovative entrepreneurial activities. At the same time, 
psychology holds that----imagination cannot achieve the true psychology of the events. Therefore, we can use the form of situational imitation cases to achieve psychological health intervention in the process of innovative and entrepreneurship education for the college students.

In teaching, the teachers can set a certain situation in which students can play their respective role, for example, to simulate "preparing to open a restaurant". Innovation and startup is a systematic and improved activity, any omission of work would lead to the failure of it. In the situation of "preparing to open a restaurant", the students need to think about the type of the restaurant----Chinese food or European food, location of the restaurant, business license, decoration, procurement equipment, employee recruitment, health permits, marketing, strategy and so on, all above requires the students to contact different industries, different institutions, different people, Knowledge of a wide range of knowledge, such as management, marketing, interior design and so on. So to speak, it is necessary to do a lot of work to complete the situational stimulation----“preparing to open a restaurant”. In this process, the students can feel their shortcomings that they need in their roles, and then they can have a better understand about the difficulties in entrepreneurial activities, and finally have a healthy psychology in the road of innovation and startup.

\subsection{Experiment of outward bound training}

Outward bound is to improve psychological ability at the utmost by stimulating activities field, arranging challenge activities. The innovative and entrepreneurial education of college students is to comprehensively improve the psychological quality of them. So, outward bound is a relative suitable method for the psychological health intervention experiment of innovative and entrepreneurial education of the college students. Colleges and universities could arrange the students to take part in the outward bound activities periodically by constructing the activity training base or being a partner of the base. The training programs in the base need to be diversified, such as team confrontation, individual ability improvement, endurance improvement, etc., which could include the specific items such as island survival, rock climbing, crossing the electric grid, etc. In the training, students' different abilities and psychological qualities can be trained. For example, rock climbing can train students' endurance and flexibility; crossing the electric grid can exercise students' decisiveness and carefulness; and isolated island survival can exercise students' teamwork and their ability of organization, and so on. By these training experiments, we can stimulate the psychological potential of the college students to the greatest extent, and finally cultivate the ability of innovation and startup of the college students.

\section{Summarization}

From the perspective of psychological health intervention and the connotation of college students' innovative and startup education, this paper discusses the specific cases of psychological health intervention in college students' innovative and startup education. In a word, the innovative and startup education of college students is one of the basic work of the educational reform in modern higher education, and the ability and quality of college students' innovation and startup is the essential foundation of their innovative and startup activities in the future. Colleges and universities need to constantly improve the quality and efficiency of innovative and startup education for the college students, and integrate more scientific and new educational methods into the innovation and startup education, so as to constantly improve the psychological quality and innovation and startup ability of college students, and to provide some help for their future innovation and startup activities according to the actual situations.

\section{Acknowledgement}

2017 Xi'an Social Science Planning Fund Project “Experimental Study on Psychological Health Intervention in Innovation and Startup Education for Colleges Students” Item no. 17PH08. 


\section{References}

[1] Qin Qin, Jiang Zhibin. On Startup Policies for College Students: Comment, Lesson and Design [J]. Journal of Chongqing University (Social Edition), 2012(03)

[2] Peng Jiajia. Investigation and Analysis of College Students' Cognition and Awareness of Startup----Taking Ten Colleges of Xianlin Area [J]. Legal System and Society, 2011(35).

[3] Cheng Peng, Yin Haohua, Liu Lan. Brief Discussion on Entrepreneurial Education of College Student [J]. Assets and Finances in Administration and Institution, 2011(02).

[4] Gao Riguang. On Influence of Individual, Family and Society to the Entrepreneurial Motivation of College Students----Empirical Research that Based on the College Students of Jiangxi Province [J]. Journal of Higher Education Management, 2011(06).

[5] Ma Bin. Brief Analysis on Entrepreneurial Education of Local Colleges and the Countermeasure [J]. Journal of Taizhou University, 2011(05). 